\title{
Individual variation in aerobic scope affects modeled vertical foraging migration in Atlantic cod Gadus morhua, but only in moderate hypoxia
}

\author{
Jane W. Behrens*, Jon C. Svendsen, Stefan Neuenfeldt, Niels G. Andersen, \\ Mikael van Deurs
}

National Institute of Aquatic Resources, Technical University of Denmark (DTU Aqua), Kemitorvet, 2800 Kgs. Lyngby, Denmark

\begin{abstract}
Vertical migration is the most widespread migration in the aquatic world, yet the mechanisms limiting the extent of this behavior are largely unknown. In the Baltic Sea, some Atlantic cod Gadus morhua perform vertical foraging migrations into severely hypoxic demersal zones where aerobic metabolism is insufficient to cover energy requirements. After foraging, the fish return to better oxygenated waters for physiological recovery and digestion. To test the influence of phenotypic variation in aerobic scope (AS; the difference between the maximum and the minimum metabolic rate) on the capacity to migrate into severely hypoxic zones, we incorporated AS into a state-dependent individual-based model simulating vertical foraging migrations of $G$. morhua. We found little effect of individual variation in AS on the capacity for vertical migration when the zone used for physiological recovery was normoxic. In contrast, when there was moderate hypoxia $\left(30 \%\right.$ air saturation, $\mathrm{O}_{2 \mathrm{sat}}$ ) in the zone used for physiological recovery, the high AS phenotype had a clear advantage because it could forage 3-4 times longer in the severely hypoxic $\left(16 \% \mathrm{O}_{2 \text { sat }}\right.$, i.e. below the threshold for aerobic metabolism of the species) demersal zone compared to the low AS phenotype. Thus, phenotypic variation in AS is only important when there is moderate hypoxia in the zone used for physiological recovery, suggesting that the influence of AS variation on the capacity for vertical migration is context dependent. We propose that elevated AS may be evolutionarily favorable when hypoxia prevails in the water column.
\end{abstract}

KEY WORDS: Physiology · Behavior - Baltic Sea • Bioenergetics · Aerobic scope · Hypoxia · Gadus morhua · Individual-based model

\section{INTRODUCTION}

Vertical migration is the most widespread migration in the aquatic world, occurring throughout the oceans and lakes and common to both vertebrates and invertebrates (Hinch et al. 2006), yet the mechanisms limiting the extent of this behavior remain uncertain. In the Baltic Sea, Atlantic cod Gadus morhua inhabit areas with combined halo-, thermo- and oxyclines (Matthäus \& Franck 1992). Interestingly, data from data-storage tags (DSTs) employed on individ-

*Corresponding author: jabeh@aqua.dtu.dk

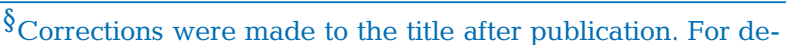
tails see www.int-res.com/abstracts/meps/v599/c_p201-208/ This corrected version: September 11, 2018 ual G. morhua have revealed that some fish perform vertical migrations into severely hypoxic demersal zones, presumably to forage (Neuenfeldt et al. 2009). In this environment, ambient oxygen levels are below the critical level for the species, and as the aerobic metabolism is insufficient to cover energy requirements, the fish will build up an oxygen debt (Schurmann \& Steffensen 1997, Plambech et al. 2013). Following the vertical foraging migration, physiological recovery and digestion occur higher in the water column, where there is normoxia or moderate

(C) The authors 2018. Open Access under Creative Commons by Attribution Licence. Use, distribution and reproduction are unrestricted. Authors and original publication must be credited.

Publisher: Inter-Research · www.int-res.com 
hypoxia. Here, G. morhua face a trade-off between favorable temperature and oxygen for digestion, while low salinity constrains the fish closer to the water surface (Schaber et al. 2009, Andersen et al. 2017). Indeed, these observations suggest that the physiological capacity of the individual may influence the temporal extent of vertical foraging migrations.

Emerging evidence indicates that individual aerobic scope $\left(\mathrm{AS}_{\text {; }}\right.$ the difference between minimal and maximal rate of aerobic metabolism) correlates with a suite of fitness-related traits in fish (Killen et al. 2012, Auer et al. 2015), highlighting the importance of AS in relation to individual performance. Considering that all aerobically fueled processes above minimal metabolic requirements compete for the available AS, we hypothesized that phenotypic variation in AS influences the temporal extent of foraging migrations into severely hypoxic demersal zones. The hypothesis was motivated by recent modeling studies using fish AS to predict (1) optimal life histories and behaviors at different temperatures (Holt \& Jørgensen 2015) and (2) species distributions and responses to changes in climate (Marras et al. 2015, McKenzie et al. 2016) and similar abiotic variables (Behrens et al. 2017). Furthermore, Del Raye \& Weng (2015) developed an aerobic scope-based habitat suitability model to forecast the response of marine fishes to simultaneous ocean acidification, warming and deoxygenation, including interactions between all 3 stressors.

To test the hypothesis that phenotypic variation in AS may influence the temporal extent of foraging migrations into severely hypoxic demersal zones, we integrated AS variation into an individual-based model (IBM) parameterized with literature-derived equations describing the physiology of G. morhua. The model assumes that vertical migration behavior is state-dependent (i.e. based on stomach fullness). By running the model for a typical range of AS phenotypes, we used the model to address 3 questions: (1) Is phenotypic variation in AS affecting foraging time in severely hypoxic demersal zones? (2) Is oxygen availability in the upper zone, where physiological recovery and digestion occur, influencing foraging time in the severely hypoxic demersal zone? (3) Are high and low AS phenotypes affected equally by the oxygen availability in the upper zone?

\section{MATERIALS AND METHODS}

To address the hypothesis that phenotypic variation in AS influences the temporal extent of foraging migrations into severely hypoxic demersal zones, we developed an IBM for adult Gadus morhua foraging in a vertically stratified water column. Model configuration and parameterization were based on published experiments and standards for bioenergetics models (all equations and parameter values are explicitly explained in Table 1, including references; see Hanson et al. 1997 regarding bioenergetic models in general). The vertical foraging migrations simulated in the model covered transitions between an upper normoxic or moderately hypoxic $(30,40,50$ or $100 \%$ air saturation, $\mathrm{O}_{2 \text { sat }}$ ) recovery zone with no food and a severely hypoxic demersal foraging zone with $16 \% \mathrm{O}_{2 \text { sat, }}$ which is below the oxygen threshold $\left(S_{\text {crit }}\right)$ for aerobic metabolism of G. morhua under most temperature conditions (Eq. 3c in Table 1) (Schurmann \& Steffensen 1997). The model was designed to produce the average daily foraging time $\left(\mathrm{h} \mathrm{d}^{-1}\right)$ integrated over a period of $20 \mathrm{~d}$ (i.e. number of hours spent foraging in the severely hypoxic demersal zone divided by 20). Foraging activity in fishes is often influenced by stomach fullness. This has been shown both in behavior optimization models (Kirby et al. 2000), in laboratory experiments (Salvanes \& Hart 1998) and in field studies on gadoids (Rindorf 2002). Therefore, the decision to make a transition between the normoxic or moderately hypoxic recovery zone and the severely hypoxic demersal zone was based on the individual stomach fullness in each time step $(t)$, using predefined stomach fullness trigger levels. Stomach fullness ( $g$ ) was derived from Eq. (4c) (Table 1) based on information about the amount of food entering and exiting the stomach (Eq. 4b,c). Stomach evacuation in a given time step was derived from the energetic cost of digesting a meal (the rate of specific dynamic action, $R_{\mathrm{SDA}}\left[\mathrm{J} t^{-1}\right]$ ) (Eq. 2c) and free AS ( $F_{t}\left[\mathrm{~J} t^{-1}\right]$, Eq. 1a). AS is defined as the maximum metabolic rate $\left(R_{\max }\left[\mathrm{J} t^{-1}\right]\right.$, Eq. 1b) minus the standard metabolic rate $\left(R_{S}\left[\mathrm{~J} t^{-1}\right]\right.$, Eq. 2a), where $R_{\max }$ is a function of both temperature and ambient oxygen conditions (Claireaux et al. 2000, Tirsgaard et al. 2015). As a result, $F_{t}$ was modeled as AS minus the cost of swimming $\left(R_{\mathrm{A}}\left[\mathrm{J} t^{-1}\right], \mathrm{Eq} .2 \mathrm{~b}\right)$ and the cost of eliminating any oxygen debt $(D[\mathrm{~J}])\left(R_{\mathrm{ED}}\right.$, Eq. 3b), where oxygen debt is also known as excess post-hypoxic oxygen consumption (Svendsen et al. 2012, Genz et al. 2013, Plambech et al. 2013). Note that $R_{\mathrm{SDA}}$ was not explicitly used in Eq. (1a) to calculate $F_{t}$. This is because whenever $F_{t}$ was insufficient to accommodate $R_{\mathrm{SDA}}$ associated with the maximum rate of digestion (i.e. calculated in Eq. 2c), a feedback loop in the model downscaled $R_{\mathrm{SDA}}$ to exactly match $F_{t}$, which in turn led to a reduced stomach evacuation in Eq. $(4 \mathrm{a}, \mathrm{b})$. Oxygen debt $(D)$ accumulated when- 
Table 1. Summary of the individual-based bioenergetics model (IBM) of an adult Atlantic cod Gadus morhua. All rate equations in the table apply to standardized $1 \mathrm{~h}$ time steps, as this is how data from experiments are commonly reported. However, in the present application of the model, time steps $(t)$ of $0.2 \mathrm{~h}$ were used to match the resolution of data recovered from the data-storage tag (DST; see 'Materials and methods' for further details). Hence, all rate values (i.e. $\mathrm{J}^{-1}$ ) were effectively divided by 5 . The rate of food acquisition $(\varepsilon)$ in the severely hypoxic demersal zone was fixed at $10 \mathrm{~g} \mathrm{~h}^{-1}$, and initiation of foraging was triggered when gut fullness reached $5 \%$ of maximum gut capacity $(\delta)$. Return to the normoxic or moderately hypoxic upper zone for physiological recovery and digestion was triggered at $50 \%$ of $\delta$

\begin{tabular}{|c|c|c|c|}
\hline Eq. no. & Explanation & Equation & Description of parameters \\
\hline $1 a, b$ & $\begin{array}{l}F_{t}=\text { free aerobic scope }\left(\mathrm{J} t^{-1}\right) \\
\text { available in a given time step } \\
\text { for energy consuming activities } \\
\text { such as digesting food } \\
R_{\max }=\text { maximum metabolic rate } \\
\left(\mathrm{J} t^{-1}\right)\end{array}$ & $\begin{array}{l}F_{t}=R_{\max }-R_{\mathrm{S}}-R_{\mathrm{A}}-R_{\mathrm{ED}} \\
R_{\max }=\left(17.29 \times T_{t}^{-0.015 \times T_{t}+1.06}+30\right) \times \\
\left(1-\mathrm{e}^{-0.035 \times O_{2 \mathrm{sat}}+0.34}\right) \\
\text { (Claireaux et al. 2000) }\end{array}$ & $\begin{array}{l}R_{\mathrm{S}} \text { is the standard metabolic rate } \\
\text { (modeled in Eq. } 2 \mathrm{a} \text { ). } R_{\mathrm{A}} \text { is the metabolic } \\
\text { cost of swimming (modeled in Eq. } 2 \mathrm{~b} \text { ). } \\
R_{\mathrm{ED}} \text { is the cost of repaying any oxygen } \\
\text { debt per time unit ( } t^{-1} \text { ) (modeled in } \\
\text { Eq. } 3 \mathrm{a} \text { ). } \\
\mathrm{O}_{2 \text { sat }} \text { is the air saturation }(\%) \text { in time } \\
\text { step } t \text { in } \mathrm{t} \text { he ambient environment. }\end{array}$ \\
\hline $2 a, b, c$ & $\begin{array}{l}R_{\mathrm{S}}=\text { standard metabolic rate }\left(\mathrm{J} t^{-1}\right) \\
\text { (i.e. metabolic rate of a resting fish) } \\
R_{\mathrm{A}}=\text { metabolic cost of swimming } \\
\left(\mathrm{J} t^{-1}\right) \\
R_{\mathrm{SDA}}=\text { metabolic cost of digesting } \\
\text { consumed food }\left(\mathrm{J} t^{-1}\right) \text { (i.e. related to } \\
\text { specific dynamic action) }\end{array}$ & $\begin{array}{l}R_{S}=\left(0.0687 \times \mathrm{e}^{0.06 \times T_{t}}\right) \times \\
\left(W^{-0.00089 \times T_{t}^{2}+0.02 \times T_{t}+0.79}\right) \times 14 \\
(\text { Tirsgaard et al. 2015) } \\
R_{\mathrm{A}}=\left(\frac{W}{1000}\right) \times(24.4 \times v+4.1) \times 14 \\
(\text { Melzner et al. 2009) } \\
R_{\mathrm{SDA}}=\rho \times M_{t} \times \alpha\end{array}$ & $\begin{array}{l}W=\text { fish weight }(\mathrm{g}) \text {. The value } 14 \text { is } \\
\text { the caloric conversion factor that takes } \\
\text { the experimental respiratory metric, } \\
\mathrm{mg} \mathrm{O}_{2} \text {, and converts it to joules. } \\
\nu=\text { swimming speed }(0.2 \text { body lengths } \\
\left.\text { [bl] s } \mathrm{s}^{-1} \text {; Schurmann \& Steffensen } 1994\right) \text {. } \\
\rho=\text { proportion of ingested energy that } \\
\text { is used to support processes related to } \\
\text { digestion }(\rho=0.15) \text { (Kerr } 1982) . M_{t}= \\
\text { amount of food evacuated in a given } \\
\text { time step (g) (see Eq. } 4 \mathrm{a}) . T_{t}=\text { ambient } \\
\text { temperature in time step } t \text { (based on } \\
\text { data from DSTs used by Neuenfeldt et } \\
\text { al. } 2009 ; T=5^{\circ} \mathrm{C} \text { in the hypoxic zone } \\
\text { and } 6^{\circ} \mathrm{C} \text { in the recovery zone). } \alpha= \\
\text { energy density of food }\left(\mathrm{J} \mathrm{g}{ }^{-1}\right) \text {. We used } \\
\alpha=4000 \mathrm{~J} \mathrm{~g}^{-1} \text {, which is applicable to } \\
\text { both fish and energy-rich invertebrates. }\end{array}$ \\
\hline $3 a, b, c$ & $\begin{array}{l}R_{\mathrm{ED}}=\text { cost of eliminating oxygen } \\
\text { debt }\left(\mathrm{J} t^{-1}\right) \\
D_{t}=\text { oxygen debt in a given time } \\
\text { step (J) } \\
S_{\text {crit }}=\text { critical } \mathrm{O}_{2 \text { sat }} \text { level (\% air } \\
\text { saturation). Below } S_{\text {crit }} \text { metabolic } \\
\text { processes run partly anaerobically } \\
\text { and oxygen debt }(D) \text { builds up }\end{array}$ & 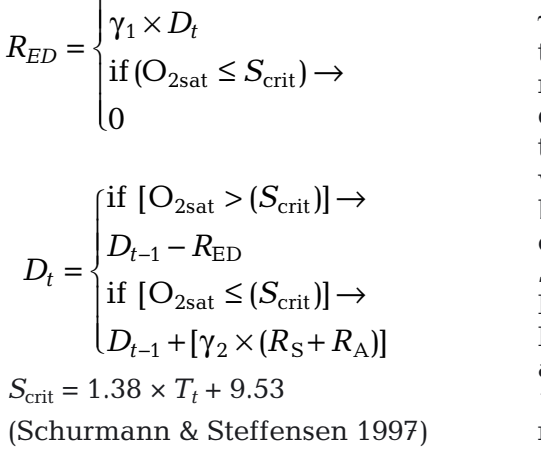 & $\begin{array}{l}\gamma_{1} \text { is a parameter that defines the frac- } \\
\text { tion of the oxygen debt that is elimi- } \\
\text { nated at each time step (if an oxygen } \\
\text { debt exists), whenever environmen- } \\
\text { tal oxygen levels are above } S_{\text {crit }} \text {. Here } \\
\text { we used } \gamma_{1}=0.25 \text { (adapted from Plam- } \\
\text { bech et al. } 2013 \text { ). } \gamma_{2}=\text { rate at which } \\
\text { oxygen debt builds up when } \mathrm{O}_{2 \text { sat }}< \\
S_{\text {crit }} \text { given as a proportion of } R_{\mathrm{S}} \text {. } \\
\text { Here we used } \gamma_{2}=0.5 \text { (adapted from } \\
\text { Plambech et al. 2013). Lastly, we } \\
\text { assumed that swimming speed was } \\
1 \text { bl s } \text { suring the vertical foraging }^{-1} \text { migrations. }\end{array}$ \\
\hline $4 a, b, c$ & $\begin{array}{l}M_{t}=\text { amount of food evacuated }(\mathrm{g}) \\
\text { in time step } t \text { after accounting } \\
\text { for limitation induced by } F_{t} \\
M_{t}^{*}=\text { potential amount evacuated }(\mathrm{g}) \\
\text { from stomach at time step } t \\
m_{t}=\text { stomach fullness }(\mathrm{g}) \text { at the } \\
\text { beginning of time step } t\end{array}$ & 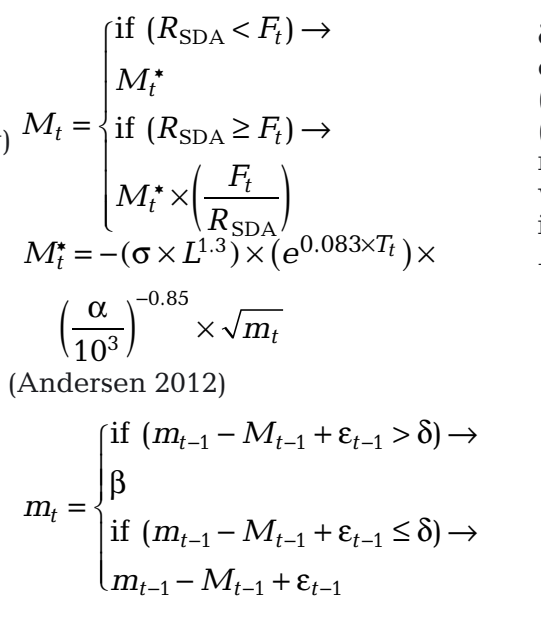 & 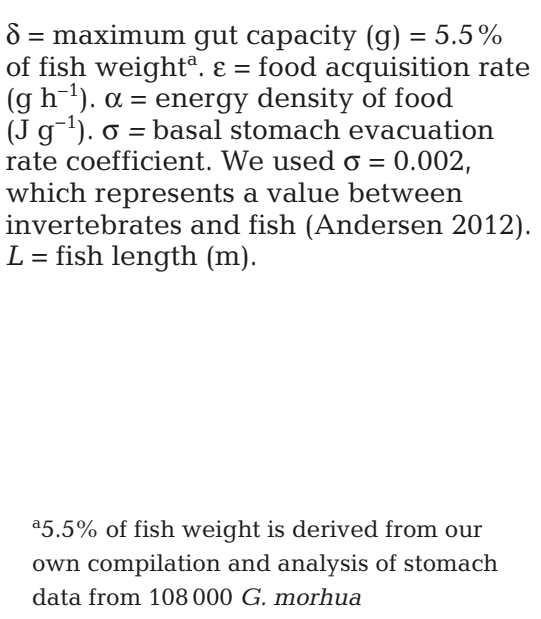 \\
\hline
\end{tabular}


ever oxygen levels dropped below $S_{\text {crit }}$ (i.e. when the fish was in the severely hypoxic demersal foraging zone). The accumulation rate was equal to $R_{\mathrm{S}}$ plus $R_{\mathrm{A}}$ (Schurmann \& Steffensen 1997, Plambech et al. 2013) and was gradually eliminated upon return to the recovery zone at a specific rate $\left(R_{\mathrm{ED}}\left[\mathrm{J} t^{-1}\right]\right.$, Eq. 3a) derived directly from experiments by Plambech et al. (2013).

To observe the different physiological dynamics that the model kept track of during the simulations, we forced the model with temperatures and oxygen levels recovered from a DST tag revealing a typical vertical migration pattern (derived from data in Neuenfeldt et al. 2009) (Fig. 1).

The final model was thereafter applied to different oxygen levels in the upper recovery zone, from moderate hypoxia to normoxia $\left(30,40,50\right.$ or $\left.100 \% \mathrm{O}_{2 \text { sat }}\right)$,

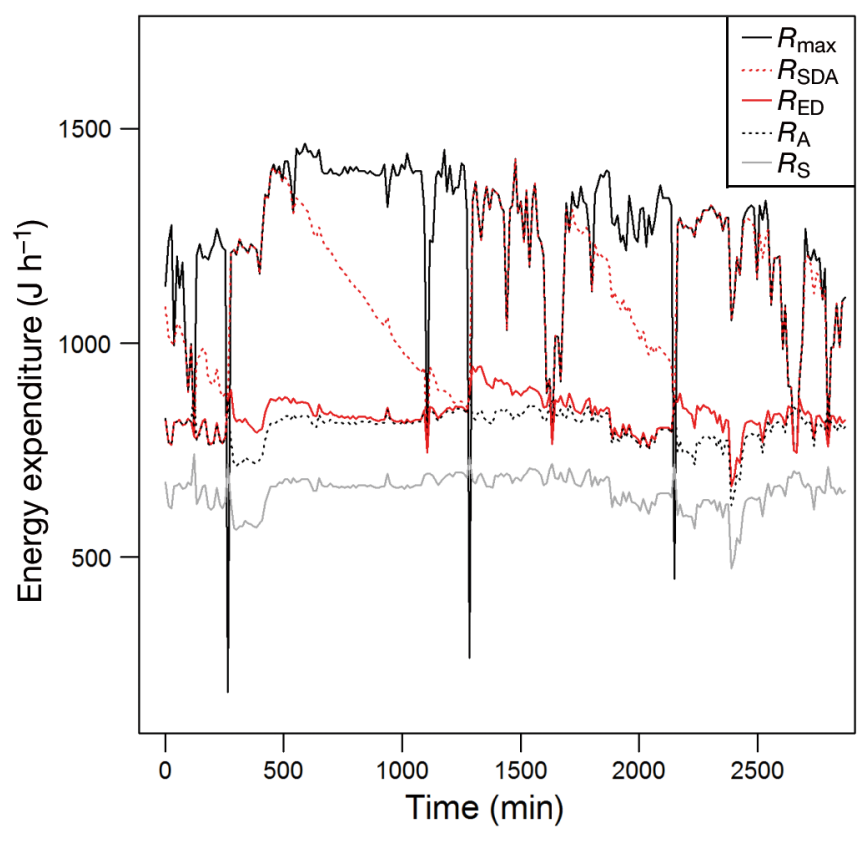

Fig. 1. Energy expenditures $\left(\mathrm{J} \mathrm{h}^{-1}\right)$ in an Atlantic cod Gadus morhua performing vertical migrations in the Baltic Sea. Shown are stacked data tracks of maximum metabolic rate $\left(R_{\max }\right.$ black $)$, cost of eliminating specific dynamic action ( $R_{\mathrm{SDA}} ;$ red dotted), cost of eliminating oxygen debt $\left(R_{\mathrm{ED} i}\right.$ red), metabolic cost of swimming $\left(R_{\mathrm{A}}\right.$ i black dotted) and standard metabolic rate $\left(R_{\mathrm{S}}\right.$ grey). Integrating over time, free aerobic scope is defined as the difference between $R_{\max }$ and $R_{\mathrm{SDA}}$. Environmental forcing (i.e. temperature and oxygen level) follows recordings by a typical data storage tag recovered from a G. morhua in the Baltic Sea (Neuenfeldt et al. 2009). The fish migrated into the severely hypoxia demersal zone 3 times within a $40 \mathrm{~h}$ period (i.e. when the $R_{\max }$ graph drops below $500 \mathrm{~J} \mathrm{~h}^{-1}$ ). In the model, the fish was foraging during each vertical migration into the severely hypoxic demersal zone, causing $R_{\mathrm{SDA}}$ and $R_{\mathrm{ED}}$ responses. Details of the model are provided in Table 1 and a continuum of different AS phenotypes, ranging from 80 to $120 \%$ of the species average (Tirsgaard et al. 2015), reflecting the typical range of phenotypic variation in AS (Norin et al. 2016). Both types of adjustments influenced mainly Eq. (1b) and involved varying the $\mathrm{O}_{2 \text { sat }}$ value $(30,40,50$ or $100 \%)$ and employing different multiplication factors on $R_{\max }$ ranging from 0.8 to 1.2 . The temperature was kept the same in all final simulations $\left(6^{\circ} \mathrm{C}\right.$ in the upper normoxic/moderately hypoxic recovery zone and $5^{\circ} \mathrm{C}$ in the severely hypoxic demersal zone). The chosen temperatures were derived from the DST tag retrieved from a G. morhua in the Bornholm Basin (Neuenfeldt et al. 2009). Fish length and weight were kept constant at $0.5 \mathrm{~m}$ and $1.2 \mathrm{~kg}$, where $1.2 \mathrm{~kg}$ corresponds to the average weight of a $0.50 \mathrm{~m}$ long $G$. morhua, which was the size of fish used in the DST study from which we derived information for the model (Neuenfeldt et al. 2009). The rate of food acquisition $(\varepsilon)$ and lower and upper stomach fullness trigger levels, determining when the fish would transition between the upper normoxic/moderately hypoxic recovery zone and the severely hypoxic demersal foraging zone, were adjusted to match consumption rates observed in the Bornholm Basin (Neuenfeldt et al. 2009) (feeding rate was $10 \mathrm{~g} \mathrm{~h}^{-1}$, and the lower and upper trigger values were $5 \%$ and $50 \%$ of the maximum gut capacity [ $\delta$ ], respectively). To examine the sensitivity of our conclusions to the choice of food acquisition rate $(\varepsilon)$ and trigger levels, model simulations were repeated with $\varepsilon$ adjusted to 8 and $12 \mathrm{~g} \mathrm{~h}^{-1}$, respectively (i.e. $\pm 20 \%$ of the observed feeding rate). Note that increasing $\varepsilon$ produces the same effect on the model output as decreasing the upper trigger level. Hence, we only varied feeding rate in the sensitivity analysis presented here.

\section{RESULTS}

When $R_{\mathrm{SDA}}$ and $R_{\mathrm{ED}}$ occurred in normoxia (i.e. $100 \% \mathrm{O}_{2 \text { sat }}$ ), the mean daily foraging time in severe hypoxia was largely unaffected by phenotypic variation in AS and varying between 1.19 and $1.28 \mathrm{~h}$ (Fig. 2; green line). In contrast, for the high AS phenotype, the foraging time was reduced by $16 \%$ (i.e. to $1.07 \mathrm{~h}$ ) when $R_{\mathrm{SDA}}$ and $R_{\mathrm{ED}}$ occurred in $30 \% \mathrm{O}_{2 \text { sat }}$ instead of normoxia, whereas the foraging time of the low AS phenotype was reduced by $\sim 79 \%$ (i.e. to $0.25 \mathrm{~h}$ ) (Fig. 2; green line versus red line) in $30 \%$ $\mathrm{O}_{\text {ssat }}$. Thus, compared to the low AS phenotype, the high AS phenotype had the physiological capacity to forage 3-4 times longer when physiological recovery 


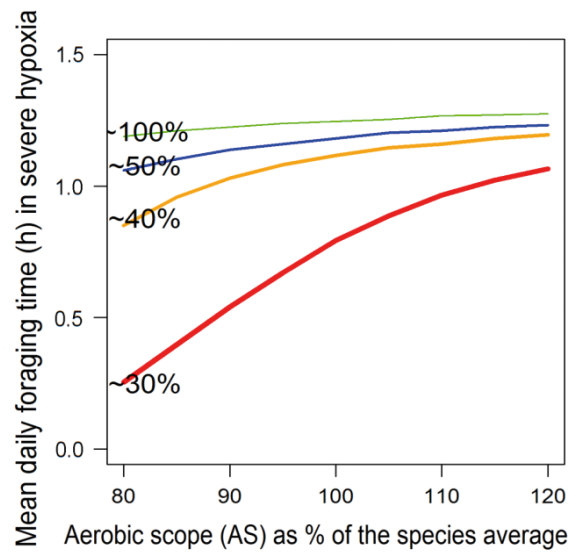

Fig. 2. Mean daily foraging time in severe hypoxia as a function of aerobic scope (AS; the difference between the maximum and the standard metabolic rate, $R_{\max }$ and $R_{\mathrm{S}}$, respectively) and oxygen levels in the upper zone of the water column where physiological recovery and digestion occur. Model details are provided in Table 1. Phenotypic variation in AS ranged between 80 and $120 \%$ of the species average (Tirsgaard et al. 2015). Oxygen levels in the upper zone of the water column ranged from $30 \% \mathrm{O}_{2 \text { sat }}$ (red line) to $100 \%$ $\mathrm{O}_{2 \text { sat }}$ (green line). Oxygen levels between 30 and $50 \% \mathrm{O}_{2 \text { sat }}$ are considered moderate hypoxia and $100 \%$ is normoxia

occurred in moderate hypoxia $\left(30 \% \mathrm{O}_{2 \text { sat }}\right)$. The average AS phenotype was intermediate in the capacity to forage in the severely hypoxic demersal zone, with the foraging time reduced by $\sim 40 \%$ when $R_{\mathrm{SDA}}$ and $R_{\mathrm{ED}}$ occurred in $30 \% \mathrm{O}_{2 \text { sat }}$ instead of normoxia (Fig. 2; green line versus red line). At intermediate levels of moderate hypoxia $\left(40-50 \% \mathrm{O}_{2 \mathrm{sat}}\right)$ in the upper zone, the foraging times also decreased with declining AS, but the effects were much less pronounced (Fig. 2; green line versus orange or blue lines, respectively). Importantly, the results were largely insensitive to

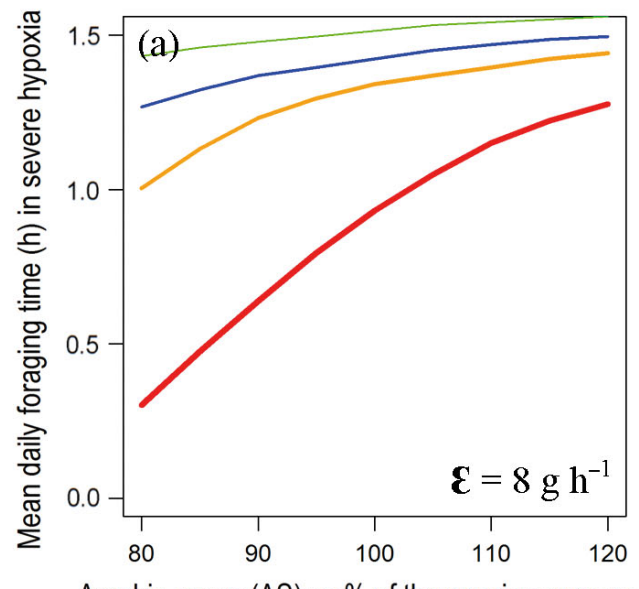

Aerobic scope (AS) as \% of the species average the choice of feeding, i.e. the relative difference in performance between the high and the low AS fish remained when feeding rate varied between 8 and $12 \mathrm{~g} \mathrm{~h}^{-1}$ (Fig. 3), corresponding to $\pm 20 \%$ of the observed feeding rate used in the model.

\section{DISCUSSION}

Our data suggest that phenotypic variation in AS plays a minor role in relation to vertical migration and foraging time in severe hypoxia when Gadus morhua return to recover and digest in normoxia. In contrast, when the fish return to moderate hypoxia upon foraging in severe hypoxia, high AS phenotypes have a clear advantage because they have the physiological capacity to forage 3-4 times longer in severely hypoxic demersal zones compared to low AS phenotypes. Consumption rate did not affect these relationships. These findings suggest that individual variation in AS may influence vertical migrations across oxygen gradients; however, the observation that high AS is only advantageous under sub-optimal conditions (i.e. moderate hypoxia in the recovery zone) is not immediately intuitive, highlighting the importance of modeling studies to reveal context dependency in fitness advantages of superior physiology. Notably, when the fish was allowed to return to normoxia to recover and digest, its physiological capacity for foraging in severe hypoxia (between 1.19 and $1.28 \mathrm{~h}$, depending on AS phenotype) corresponds well with actual field observations derived from individually DST-tagged G. morhua (Neuenfeldt et al. 2009), indicating a degree of realism in our model.

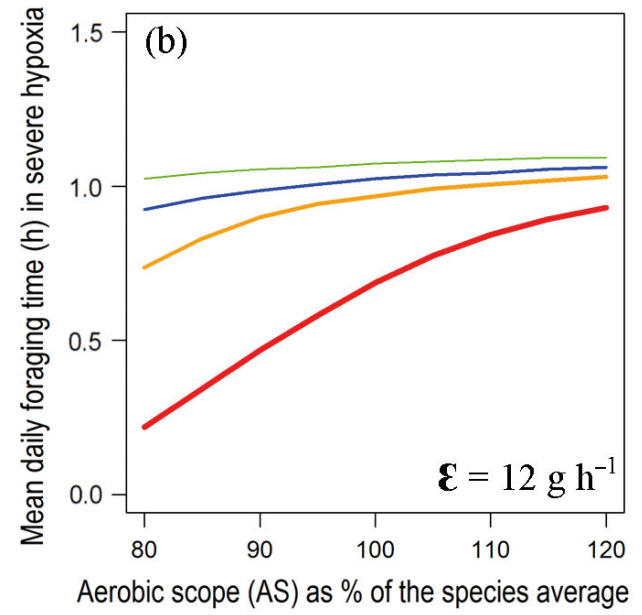

Fig. 3. Sensitivity of the model to the choice of feeding rate. Model configurations corresponded to the configurations used in Fig. 2, except for the food rate acquisition rate ( $\varepsilon$, which enters the model in Eq. (4c) in Table 1 . (a) $\varepsilon=8 \mathrm{~g} \mathrm{~h}^{-1}$, (b) $\varepsilon=12 \mathrm{~g} \mathrm{~h}{ }^{-1}$ 
The phenotypic variation in individual AS may reflect both gill and cardiac performances (Wilson et al. 1994, Claireaux et al. 2005, Eliason et al. 2011, Casselman et al. 2012, Rosewarne et al. 2014, Hess et al. 2017). Moreover, high AS may also relate to higher hematocrit levels (with more erythrocytes enhancing the blood oxygen-carrying capacity) as observed in G. morhua with hemoglobin genotype HbI2/2 (reviewed by Ross et al. 2013). Interestingly, only some Baltic G. morhua undertake brief foraging migrations into the severely hypoxic bottom waters (Neuenfeldt et al. 2009). Whether it is the fish possessing HbI-2/2 should be investigated in the future, not least considering that this genotype presumably exhibits superior oxygen transport capabilities under hypoxic conditions (Ross et al. 2013). Nevertheless, the mechanisms allowing for a higher AS may entail an additional cost for the high AS fish, included in the $R_{\mathrm{S}}$. In a recent study, elevated $R_{\max }$ and AS were associated with elevated $R_{\mathrm{S}}$ across a broad interspecific comparison (Killen et al. 2016). This would suggest an additional energetic cost associated with elevated AS (the cost of a higher $R_{\mathrm{S}}$ ). However, whether an elevated $R_{\mathrm{S}}$ is a prerequisite for elevated AS in intraspecific comparisons remains less clear. For example, Auer et al. (2015) did not identify a relationship between $R_{\mathrm{S}}$ and AS in brown trout Salmo trutta, indicating no or limited additional energetic costs of having a higher AS. Whether $R_{\mathrm{S}}$ and AS are correlated positively in G. morhua remains unclear, warranting further studies.

This study not only provides novel findings on $G$. morhua, but also presents a mechanistic modeling framework for future studies. The model can be adapted to many other aquatic organisms facing the challenges of stratified environments, provided that sufficient energetic and behavioral information exists to ensure solid model parameterization. Using the model framework, effects of intraspecific variation in traits besides AS (e.g. digestive capacity and $S_{\text {crit }}$ ) on other performance measures could be tested.

In the present study, we used fish of $1.2 \mathrm{~kg}$, corresponding to the average weight of a $50 \mathrm{~cm} \mathrm{G}$. morhua, which was the body size of the fish used in the DST study from which we derived information for the model. Preliminary model runs with fish sizes between $600 \mathrm{~g}$ and $2.5 \mathrm{~kg}$ (i.e. various sizes of adult G. morhua) did not alter the results from the model. It is uncertain if juvenile conspecifics undertake comparable vertical migrations, and we did not test the model with sizes of fish corresponding to juvenile life stages. However, even though the magnitude of AS may differ between life stages in G. morhua and other fish species (Killen et al. 2007, Tirsgaard et al. 2015), we have no reason to believe that intraspecific variance in AS would be found only in certain size groups of fish.

Consistent with our findings, laboratory studies on snapper (silver seabream Pagrus auratus) have shown that low AS phenotypes exhibit reduced hypoxia tolerance and are more likely to avoid severe hypoxia (Cook et al. 2011), highlighting the role of AS in terms of behavioral decision making. Moreover, Herbert et al. (2011) also supported our findings by demonstrating that G. morhua are more prone to spend time in severe hypoxia when provided access to a normoxic refuge.

Our data are consistent with the conjecture that fitness-related advantages of various metabolic phenotypes may be context dependent (Norin et al. 2016). For example, the optimal combination of $R_{\mathrm{S}}$ and AS for somatic growth may depend on food availability (Auer et al. 2015). Adding environmental variation to the context dependency, we found that high AS phenotypes may have a foraging advantage when moderate hypoxia prevails in the upper zone where physiological recovery and digestion occur. Importantly, the advantage is eliminated when the upper zone is normoxic. The cause-effect explanation for enhanced foraging performance of high AS fish is found in the recovery phase. More specifically, even though the AS of all fish is reduced in moderate hypoxia (Claireaux et al. 2000, Svendsen et al. 2012), the AS of high AS fish is still proportionally larger, allowing high AS fish to recover faster from the oxygen debt and complete $R_{\mathrm{SDA}}$ quicker as compared to low AS fish. Thus, the enhanced foraging performance of high AS fish is explained by faster recovery and completion of $R_{\mathrm{SDA}}$ that allow the high AS fish to engage in another foraging excursion into severe hypoxia after a shorter time span than the low AS fish.

In the Baltic Sea, G. morhua occur in highly stratified areas where even small vertical movements often result in changes in oxygen contents (Neuenfeldt et al. 2009). Dissolved oxygen concentration not only sets the lower distribution limits for G. morhua, but the fish also face a trade-off between favorable temperature and oxygen for digestion, causing an accumulation of fish at depths between 55 and $65 \mathrm{~m}$ within the oxy- and thermocline (Andersen et al. 2017). Here, G. morhua experience oxygen contents ranging between 25 and $80 \% \mathrm{O}_{2 \text { sat }}$ (increasing toward the surface). The upper distribution is further constrained by low salinities, forcing the fish to parts of the water column where oxygen content is re- 
duced (Schaber et al. 2009). Over the past 2 decades, the spatial extent of hypoxic zones in the Baltic Sea has increased 5-fold (Carstensen et al. 2014), and on a global scale, oceanic oxygen content is also decreasing (Schmidtko et al. 2017). While these changes are likely to have severe ecosystem effects, predicting the direct deoxygenation-induced changes on ecosystems requires data that are derived from individual organisms, which can then be scaled to communities, food webs and fish populations (Breitburg et al. 2018) We propose that the high AS phenotypes will have an advantage in a future, more hypoxic water column, because this phenotype exhibits faster recovery from the oxygen debt and quicker completion of the $R_{\mathrm{SDA}}$ than low $\mathrm{AS}$ fish. The high AS phenotype allows increased frequency of foraging excursions into severely hypoxic bottom waters and thus provides better access to needed food resources.

Acknowledgements. J.W.B. acknowledges funding from the Carlsberg Foundation (2008_01_0388) and M.v.D. acknowledges funding from the Danish Council for Independent Research (DFF-4002-00114).

\section{LITERATURE CITED}

Andersen NG (2012) Influences of potential predictor variables on gastric evacuation in Atlantic cod Gadus morhua feeding on fish prey: parameterization of a generic model. J Fish Biol 80:595-612

Andersen NG, Lundgren B, Neuenfeldt S, Beyer JE (2017) Diel vertical interactions between Atlantic cod Gadus morhua and sprat Sprattus sprattus in a stratified water column. Mar Ecol Prog Ser 583:195-209

Auer SK, Salin K, Rudolf AM, Anderson GJ, Metcalfe NB (2015) The optimal combination of standard metabolic rate and aerobic scope for somatic growth depends on food availability. Funct Ecol 29:479-486

Behrens JW, van Deurs M, Christensen EAF (2017) Evaluating dispersal potential of an invasive fish by the use of aerobic scope and osmoregulation capacity. PLOS ONE 12:e0176038

Breitburg D, Levin LA, Oschlies A, Grégoire M and others (2018) Declining oxygen in the global ocean and coastal waters. Science 359:eaam7240

* Carstensen J, Andersen JH, Gustafsson BG, Conley DJ (2014) Deoxygenation of the Baltic Sea during the last century. Proc Natl Acad Sci USA 111:5628-5633

* Casselman MT, Anttila K, Farrell AP (2012) Using maximum heart rate as a rapid screening tool to determine optimum temperature for aerobic scope in Pacific salmon Oncorhynchus spp. J Fish Biol 80:358-377

* Claireaux G, Webber DM, Lagardère JP, Kerr SR (2000) Influence of water temperature and oxygenation on the aerobic metabolic scope of Atlantic cod (Gadus morhua). J Sea Res 44:257-265

* Claireaux G, McKenzie DJ, Genge AG, Chatelier A, Aubin J, Farrell AP (2005) Linking swimming performance, car- diac pumping ability and cardiac anatomy in rainbow trout. J Exp Biol 208:1775-1784

Cook DG, Wells RMG, Herbert NA (2011) Anaemia adjusts the aerobic physiology of snapper (Pagrus auratus) and modulates hypoxia avoidance behaviour during oxygen choice presentations. J Exp Biol 214:2927-2934

* Del Raye G, Weng KC (2015) An aerobic scope-based habitat suitability index for predicting the effects of multidimensional climate change stressors on marine teleosts. Deep Sea Res Part II Top Stud Oceanogr 113:280-290

Eliason EJ, Clark TD, Hague MJ, Hanson LM and others (2011) Differences in thermal tolerance among sockeye salmon populations. Science 332:109-112

Genz J, Jyde MB, Svendsen JC, Steffensen JF, Ramløv H (2013) Excess post-hypoxic oxygen consumption is independent from lactate accumulation in two cyprinid fishes. Comp Biochem Physiol A Mol Integr Physiol 165: $54-60$

Hanson PC, Johnson TB, Schindler DE, Kitchell JF (1997) Fish bioenergetics 3.0. Sea Grant Tech Rep WISCUT97-001. University of Wisconsin, Sea Grant Institute, Madison, WI

*Herbert NA, Skjæraasen JE, Nilsen T, Salvanes AGV, Steffensen JF (2011) The hypoxia avoidance behaviour of juvenile Atlantic cod (Gadus morhua L.) depends on the provision and pressure level of an $\mathrm{O}_{2}$ refuge. Mar Biol 158:737-746

* Hess S, Prescott LJ, Hoey AS, McMahon SA, Wenger AS, Rummer JL (2017) Species-specific impacts of suspended sediments on gill structure and function in coral reef fishes. Proc R Soc B 284:20171279

Hinch SG, Cooke SJ, Healey MC, Farrell AP (2005) Behavioural physiology of fish migrations: salmon as a model approach. In: Sloman K, Balshine S, Wilson R (eds) Fish physiology, Vol 24. Behaviour and physiology of fish. Associated Press, p 239-295

* Holt RE, Jørgensen C (2015) Climate change in fish: effects of respiratory constraints on optimal life history and behaviour. Biol Lett 11:20141032

KKerr SR (1982) Estimating the energy budgets of actively predatory fishes. Can J Fish Aquat Sci 39:371-379

Killen SS, Costa I, Brown JA, Gamperl AK (2007) Little left in the tank: metabolic scaling in marine teleosts and its implications for aerobic scope. Proc R Soc B 274:431-438

KKillen SS, Marras S, Steffensen JF, McKenzie DJ (2012) Aerobic capacity influences the spatial position of individuals within fish schools. Proc R Soc B 279:357-364

* Killen SS, Glazier DS, Rezende EL, Clark TD, Atkinson D, Willener AST, Halsey LG (2016) Ecological influences and morphological correlates of resting and maximal metabolic rates across teleost fish species. Am Nat 187 : 592-606

K Kirby DS, Fiksen Ø, Hart PJB (2000) A dynamic optimisation model for the behaviour of tunas at ocean fronts. Fish Oceanogr 9:328-342

Marras S, Cucco A, Antognarelli F, Azzurro E and others (2015) Predicting future thermal habitat suitability of competing native and invasive fish species: from metabolic scope to oceanographic modelling. Conserv Physiol 3:cou059

Matthäus W, Franck H (1992) Characteristics of major Baltic inflows - a statistical analysis. Cont Shelf Res 12: 1375-1400

*McKenzie DJ, Axelsson M, Chabot D, Claireaux G and others (2016) Conservation physiology of marine fishes: 
state of the art and prospects for policy. Conserv Physiol 4:cow046

Melzner F, Göbel S, Langenbuch M, Gutowska MA, Pörtner HO, Lucassen M (2009) Swimming performance in Atlantic Cod (Gadus morhua) following long-term (4-12 months) acclimation to elevated seawater $\mathrm{PCO}_{2}$. Aquat Toxicol 92:30-37

Neuenfeldt S, Andersen KH, Hinrichsen HH (2009) Some Atlantic cod Gadus morhua in the Baltic Sea visit hypoxic water briefly but often. J Fish Biol 75:290-294

Norin T, Malte H, Clark TD (2016) Differential plasticity of metabolic rate phenotypes in a tropical fish facing environmental change. Funct Ecol 30:369-378

Plambech M, van Deurs M, Steffensen JF, Tirsgaard B, Behrens JW (2013) Excess post-hypoxic oxygen consumption in Atlantic cod Gadus morhua. J Fish Biol 83: 396-403

Rindorf A (2002) The effect of stomach fullness on food intake of whiting in the North Sea. J Fish Biol 61: 579-593

Rosewarne PJ, Svendsen JC, Mortimer RJG, Dunn AM (2014) Muddied waters: suspended sediment impacts on gill structure and aerobic scope in an endangered native and an invasive freshwater crayfish. Hydrobiologia 722: $61-74$

Ross SD, Behrens JW, Brander K, Methling C, Mork J (2013) Haemoglobin genotypes in cod (Gadus morhua L): their geographic distribution and physiological significance. Comp Biochem Physiol A Mol Integr Physiol 166:158-168

Editorial responsibility: Myron Peck, Hamburg, Germany
Salvanes AGV, Hart PJB (1998) Individual variability in state-dependent feeding behaviour in three-spined sticklebacks. Anim Behav 55:1349-1359

* Schaber M, Hinrichsen HH, Neuenfeldt S, Voss R (2009) Hydroacoustic resolution of small-scale vertical distribution in Baltic cod Gadus morhua-habitat choice and limits during spawning. Mar Ecol Prog Ser 377:239-253

Schmidtko S, Stramma L, Visbeck M (2017) Decline in global oceanic oxygen content during the past five decades. Nature 542:335-339

* Schurmann H, Steffensen J (1994) Spontaneous swimming activity of Atlantic cod Gadus morhua exposed to graded hypoxia at three temperatures. J Exp Biol 197:129-142

Schurmann H, Steffensen JF (1997) Effects of temperature, hypoxia and activity on the metabolism of juvenile Atlantic cod. J Fish Biol 50:1166-1180

* Svendsen JC, Steffensen JF, Aarestrup K, Frisk M, Etzerodt A, Jyde M (2012) Excess posthypoxic oxygen consumption in rainbow trout (Oncorhynchus mykiss): recovery in normoxia and hypoxia. Can J Zool 90:1-11

* Tirsgaard B, Behrens JW, Steffensen JF (2015) The effect of temperature and body size on metabolic scope of activity in juvenile Atlantic cod Gadus morhua L. Comp Biochem Physiol A Mol Integr Physiol 179:89-94

* Wilson RW, Bergman HL, Wood CM (1994) Metabolic costs and physiological consequences of acclimation to aluminum in juvenile rainbow trout (Oncorhynchus mykiss). 2: Gill morphology, swimming performance, and aerobic scope. Can J Fish Aquat Sci 51:536-544

Submitted: August 24, 2017; Accepted: May 7, 2018 Proofs received from author(s): June 12, 2018 